\title{
Inovasi Seni Pertunjukan Drama Gong Pada Era Digital
}

\author{
I Wayan Sugita ${ }^{1}$ I Gede Tilem Pastika ${ }^{2}$ \\ ${ }^{1,2}$ Fakultas Dharma Acarya, Universitas Hindu Negeri I Gusti Bagus Sugriwa, Denpasar \\ ${ }^{1}$ wayansugita2@gmail.com; ${ }^{2}$ tilempastikaigede@gmail.com
}

Artikel ini bertujuan membahas inovasi drama gong pada era digital dewasa ini. Sebagai hasil kajian kualitatif, pengumpulan data dilakukan melalui observasi, wawancara mendalam dengan pelaku seni dan penggemar drama gong, dan studi dokumentasi dengan mengkaji kembali lima kisah drama gong yang ditayangkan oleh Bali TV, TVRI Bali dan channel Youtube tahun 2020 dan 2021. Analisis deskriptif kualitatif dilakukan dengan menerapkan teori semiotika dan teori interasionisme simbolik. Hasil penelitian menunjukkan, eksistensi drama gong sampai dekade 2000-an telah mengalami inovasi, meliputi: (1) kemasan cerita; (2) regenerasi pemain dengan melibatkan generasi muda Bali; (3) dialog, (4) setting/tata panggung; (5) adanya kolaborasi dengan seniman non drama gong; dan (6) pemanfaatan teknologi digital dalam proses pengemasan dan penyaluran pertunjukan drama gong. Inovasi drama gong dalam dekade 2000-an ini mengindiasikan bahwa seni tradisional berbahasa Bali ini tetap eksis dan mampu mengikuti perkembangan zaman. Inovasi drama gong model baru memperoleh sambutan positif dari masyarakat Bali, termasuk penggemar drama gong dari kalangan anak muda Bali.

Kata kunci: inovasi, drama gong, era digital

\section{Innovation of The Drama Gong Performing Arts in The Digital Era}

This article aims to discuss the innovation of drama gong in today's digital era. As a result of the qualitative study, data collection was carried out through observation, in-depth interviews with artists and fans of drama gongs, and a documentary study by reviewing five stories of drama gongs broadcast by Bali TV, TVRI Bali, and Youtube channels in 2020 and 2021. Qualitative descriptive analysis This is done by applying the theory of semiotics and the theory of symbolic interactionism. The results of the research show that the existence of drama gong until the 2000s decade has experienced innovations, including: (1) story packaging; (2) regeneration of players by involving the younger generation of Bali; (3) dialogue, (4) setting/stage arrangement; (5) collaboration with non-drama gong artists; and (6) the use of digital technology in the process of packaging and distributing drama gong performances. The innovation of the drama gong in the decade of the 2000s indicated that this traditional Balinese art still exists and can keep up with the times. The innovation of the new drama gong model received a positive response from the Balinese people, including the young Balinese drama gong fans.

Keywords: innovation, drama gong, digital era

Proses Review : 1 - 30 Juni 2021, Dinyatakan Lolos: 15 Juli 2021 


\section{PENDAHULUAN}

Diantara seni pertunjukan tradisional yang digemari oleh masyatakat Bali adalah drama gong. Drama gong pernah mengalami masa kejayaannya dalam dekade 1970-an dan 1980-an, menjadi tontonan favorit masyarakat Bali. Masa keemasan drama gong ini setidaknya ditandai oleh tiga hal: drama gong menemukan bentuknya sebagai seni drama berdialog dengan iringan gamelan gong kebyar; drama gong merajai panggung-panggung pentas kesenian di seluruh Bali dan para pemain utamanya diberlakukan seperti selebritis; dan gengsi drama gong di mata masyarakat Bali mengalahkan semua bentuk seni pertunjukan tradisi Bali lainnya (Sugiartha, 2006; Dibia, 2012).

Menurut Putra (2008) secara historis, cikal bakal drama gong sudah ada sejak akhir 1950-an, berupa bentuk campuran (hibriditas) dari teater Barat, sandiwara, stambul, dan janger. Pentas diiringi gamelan Bali, dialog dalam bahasa campuran bahasa Indonesia dan Bali, dan pemain menggunakan pakaian tradisional Bali. Oleh karena seni pertunjukan ini merupakan campuran antara tradisional dan modern, maka dia disebut dengan istilah "drama klasik" atau "drama" saja. Nama drama gong belum muncul walau dalam pementasan drama terdahulu mengambil kisah "Mayadenawa" diiringi gamelan gong (Putra, 2009; Atmaja 2009). Karena unsur teater klasik masih kuat, kesenian ini lebih disebut sebagai drama klasik pada awalnya, kemudian pertama kali diganti menjadi drama gong oleh I Gusti Bagus Nyoman Panji (Sugita, 2016).

Dalam dekade 1990-an kepopuleran drama gong mulai pudar dan kalah bersaing dengan aneka hiburan modern yang ditayangkan televisi dan media online. Seni pertunjukan drama gong mulai meredup dan semakin jarang dipentaskan langsung menghibur penggemarnya. Disamping sebagai tontonan yang menghibur penggemarnya, drama gong juga sebagai tuntunan. Dalam setiap pertunjukan drama gong selalu ada pesan-pesan moral, baik yang menyangkut tattwa (filsafat) maupun susila (etika). Pesan-pesan itu bisa disampaikan, baik secara terang-terangan atau vulgar maupun dibungkus atau dikemas dalam bentuk bahasa sindiran, penuh humor (Sugita, 2020). Meredupnya kehidupan seni pertunjukan drama gong berarti proses pewarisan nilai-nilai tradisi kepada generasi penerus di Bali melalui seni tradisi ini menjadi terhambat. Upaya edukasi bahasa dan sastra Bali melalui drama gong menjadi tidak intensif lagi.

Pada era globalisasi ini pengaruh hiburan dunia maya datang demikian deras, yang secara langsung maupun tidak langsung bisa meminggirkan keberadaan seni tradisional Bali, termasuk drama gong. Pada era teknologi digital ini begitu banyak kesenian modern yang dapat dinikmati, baik melalui media televisi maupun melalui gadget (hanphone). Malalui siaran streaming TV dan tayangan Youtube para remaja Bali cenderung lebih menyukai aneka hiburan modern termasuk film, musik dan online game yang bisa dinikmati setiap saat lewat gadget mereka tanpa dibatasi truang dan waktu. Pada saat yang sama mereka secara langsung maupun tidak langsung meninggalkan jenis kesenian tradisioan Bali termasuk drama gong (Sugita,2021).

Melihat keberadaan drama gong yang semakin terpinggirkan oleh kesenian modern tersebut maka sebagian seniman Bali pasca dekade 2000-an melakukan inovasi seni pertunjukan drama gong. Inovasi drama gong merupakan bagian dari upaya mempertahankan identitas budaya Bali. Masyarakat Bali harus mampu mempertahankan identitas budayanya tanpa harus terseret terlalu larut dalam arus globalisasi dengan jalan melestarikan budaya lokal yang tinggi. Menurut Sedyawati (2007:37) mempertahanan budaya lokal adalah kemampuan sebuah kebudayaan untuk mempertahankan jatidirinya, tidak dengan menolak segala unsur asing dari luarnya, melainkan dengan menyaring, memilih, dan jika perlu memodifikasi unsur-unsur budaya luar sehingga tetap sesuai dengan karakter dan citra bangsa.

Diantara kelompok seniman drama gong yang melakukan inovasi tersebut adalah Paguyuban Drama Gong Sancaya Dwipa Bangli, Paguyuban Drama Gong Duta Bon Bali dan Sanggar Kayon Gianyar. Disamping aspek cerita, dialog dan tata pentasnya, inovasi drama gong juga menyangkut proses pengemasan dan penyaluran pertunjukannya melalui media digital, yakni media televisi dan channel Youtube.

Memasuki era 4.0 dewasa ini, seni pertunjukan Drama Gong telah mengalami inovasi dan direvitalisasi dan dikembangkan sesuai perkembangan teknologi digital. Disamping melestarikan seni budaya tradisional sebagai identitas budaya Bali, inovasi drama gong ini juga sebagai bentuk kontra hegemoni terhadap aneka hiburan modern seperti musik, film, dan game online yang tersedia di media digital dewasa ini (Sugita, 2021). Kecanggihan teknologi digital seperti sound system, tata lampu, LCD telah digunakan sebagai alat bantu untuk menunjang pementasan drama gong dan seni budaya tradisional lainnya. Selain itu, teknologi digital berupa web sites - jaringan internet juga dapat dijadikan sebagai ajang sosialisasi dan pemasaran karya seni-budaya itu sendiri dalam sekala global (Ruastiti, 2020). Sehubungan dengan upaya inovasi drama gong yang telah memanfaatkan teknologi digital tersebut, maka karya ilmiah ini membahas: (1) Bagaimana inovasi drama gung di era digital dewasa ini?; (2) Bagaimana respon masyarakat Bali terhdap inovasi drama gong tersebut?. 


\section{METODE PENELITIAN}

Artikel ini merupakan hasil penelitian kualitatif tentang keberadaan seni pertunjukan drama gong di Bali yang ada di Kota Denpasar, Kabupaten Bangli dan Kabupaten Gianyar. Pengumpulan data dilakukan melalui observasi terhadap tayangan drama gong di media TV dan Youtube, wawancara mendalam dengan pelaku seni dan penggemar drama gong, dan studi dokumentasi dengan mengkaji kembali lima kisah drama gong yang ditayangkan oleh Bali TV, TVRI Bali dan channel Yotube tahun 2000 dan 2021 (Tabel 1).

Tabel 1. Lima Kisah Drama Gong Pasca Dekade 2000-an

\begin{tabular}{llll}
\hline No. & Kisah & Grup drama gong & $\begin{array}{l}\text { Media saluran } \\
\text { (tahun) }\end{array}$ \\
\hline 1 & $\begin{array}{l}\text { Manik } \\
\text { Gesing Buluh }\end{array}$ & $\begin{array}{l}\text { Sanggar Sancaya } \\
\text { Dwipa, Bangli }\end{array}$ & $\begin{array}{l}\text { TVRI BALI, } \\
\text { Youtube } \\
(2020)\end{array}$ \\
\hline 2 & Ni Luh & Sanggar Sancaya & TVRI BALI, \\
& Gadung & Dwipa, Bangli & $\begin{array}{l}\text { Youtube } \\
(2021)\end{array}$ \\
\hline 3 & Nila Warsiki & Sanggar Duta Bon & TVRI BALI, \\
& & Bali, Gianyar & $\begin{array}{l}\text { Youtube } \\
(2021)\end{array}$ \\
\hline 4 & Jayaprana & Sanggar Kayon & Youtube, Bali \\
& & Gianyar/Sekdut & TV (2020/2021) \\
& & Denpasar & \\
\hline 5 & Cilinaya & Sanggar Kayon & Youtube, Bali \\
& & Gianyar/sekdut & TV (2021) \\
& & Denpsar & \\
\hline
\end{tabular}

Sumber: diolah dari data lapangan

Pemilihan objek kajian drama gong tersebut didasarkan pada beberapa alasan: (1) kelima kisah drama gong terplihih sebagai sampel kajian telah mengalami inovasi, baik dari segi kemasan cerita, dialog, teknologi pendukung dan tata panggungnya; (2) kelima kisah drama gong tersebut dikemas dan ditayangkan melalui media digital (TV dan Youtube); dan (3) kelima kisah drama gong tersebut memperoleh respon yang positif oleh penggemarnya.

Data yang berhasil diperoleh kemudian dianalisis dengan menerapkan teori semiotika dan teori interaksionime simbolik. Semiotika merupakan teori tentang tanda (Pateda 200; Sobur, 2004). Isi dialog, adegan, penampilan drama gong adalah sebagai tanda untuk diterjemahkan lebih lanjut dalam kajian ini. Selanjutnya, untuk memahami respon penonton terhadap pertunjukan drama gong diterapkan teori interaksionisme simbolik. Inti teori interksionisme simbolik adalah bahwa interaksi manusia dengan sesamanya dipengaruhi oleh simbol-simbol tertentu (Riyadi, 2001), termasuk isi dialog, adegan dalam pertunjukan drama gong yang mempengaruhi pikiran dan tindakan penontonnya.

\section{ANALISIS DAN INTEPRETASI DATA}

\section{Inovasi Seni Pertunjukan Drama Gong di Era Digital}

Revolusi industri fase keempat (4.0) kini diwarnai dengan berkembangnya digitalisasi dan otomatisasi, yakni suatu perpaduan antara internet dengan manufaktur. Proses yang terjadi adalah perubahan sosial dan kebudayaan yang terjadi secara cepat, menyangkut dasar kebutuhan pokok (needs) dengan keinginan (wants) masyarakat. Dasar perubahan ini sebenarnya adalah pemenuhan hasrat keinginan pemenuhan kebutuhan manusia secara cepat dan berkualitas. Oleh sebab itu, dalam era revolusi industri banyak mengubah cara kerja manusia dari penggunaan manual menjadi otomatisasi atau digitalisasi (Schlechtendahl,et all, 2015: 145).

Gempuran globalisasi di era ditigal ini antara lain berupa semakin maraknya seni-budaya modern (media hiburan) yang hadir bersama era 4.0 di tengah-tengah kehidupan masyarakat Bali secara langsung maupun tidak langsung telah memarginalkan keberadaan seni pertunjukan drama gong. Upaya penyelamatan dan revitalisasi drama gong perlu dilakukan mengingat seni pertunjukan ini telah menjadi bagian dari identitas budaya masyarakat Hindu Bali. Di era globalisasi saat ini, budaya lokal memiliki kesempatan untuk bangkit mewarnai budaya nasional dan budaya global. Keberadaan budaya lokal memiliki peluang besar sebagai pembentuk identitas budaya baru, dengan melakukan berbagai upaya inovasi (Ruastiti,2020).

Dalam upaya menjaga eksistensi dan mengembangkan budaya lokal sesuai tuntutan zaman, maka sebagian paguyuban drama gong di Bali terus berupaya melakukan inovasi. Inovasi mendasar yang dilakukan adalah dengan mengembangkan manajemen pementasan seni pertunjukan drama gong yang bukan hanya siap pentas secara langsung off-line, tetapi juga kemasan pentas drama gong secara online - ditayangkan melalui TV dan channel Youtube. Manajemen pementasan drama gong memang harus menyesuaian perkembangan teknologi digital dewasa ini seperti pernyataan seorang informan, pecinta drama gong dan pemerhati budaya Bali berikut:

"Sesuai tantangan zaman, seniman drama gong terus berinovasi, meningkatkan kapasitasnya, agar kisah drama gong dan ditampilkan bisa diterima penontonnya. Beberapa Sanggar drama gong di Bali, saya amati terus berinovasi dengan mengemas model drama gong model baru, dengan melibatkan pemain generasi muda Bali (I Nyoman Rema, 38 tahun)."

Inovasi drama gong mencakup beberapa hal. Pertama, pengemasan kisah (lelampahan) drama gong. Dibia $(2007,1)$, menguraikan bahwa lampahan diartikan sebagai sebuah kisah atau cerita yang dijalankan, dituturkan, atau dilakonkan di atas pentas. Guna menambah variasi, maka 
berbagai inovasi lakon cerita dilakukan seperti mengambil kutipan cerita Mahabarata, Panji Malat dan turunannya seperti beberapa cerita rakyat, seperti Keong Mas, Ande-ande Lumut, dan Golek Kencana. Lampahan yang dibawakan seni pertunjukan tradisional Bali dijiwai oleh prinsip keseimbaangan atau keselarasan yang diwujudkan dengan prinsip rwa bhineda, dua kekuatan berbeda positifnegatif, atas-bawah, baik-buruk, yang saling berkaitan dan saling membutuhkan (Dibia, 2007, 2). Lampahan seni pertunjukan tradisional Bali juga didasarka pada nilai humanis dan religius seperti disebutkan dalam tembang macapat. Nilai humanis ini antara lain diwujudkan dalam bentuk gotong royong, persaudaraan, persahabatan, dan kerukunan, selanjutnya nilai spiritual adalah ajaran agama untuk mendapatkan keseimbangan sekala dan niskala (Suarta, 2018).

Lakon ciptaan baru yang dipentaskan drama gong berbeda dengan lakon teater tradisional yang tidak dikenal siapa penciptanya. Lakon Jayaprana-Layonsari adalah sebuah lakon klasik yang padamulanya digunakan untuk sendratari. Akan tetapi, Anak Agung Raka Payadnya menggubah lakon itu menjadi lakon drama gong yang dilengkapi dengan sinopsisnya. Di samping itu pula lakon Dukuh Suladri, digubah menjadi lakon drama gong. Menurut Payadnya, lakon Jayaprana-Layonsari sangat digemari penonton Gianyar saat drama gong pertama kali ia dipentaskan. Hal itu terbukti, ketika lakon itu dipentaskan pertama kali di jaba sisi Pura Abianbase pada 24 Februari 1966, penonton memberikan sambutan hangat (Sugita,2016:16). Perubahan lakon sering dilakukan oleh sekaa drama gong di Gianyar untuk memenuhi permintaan pasar sehingga grup drama ini sudah memiliki lebih dari seratus lakon yang dipentaskan (Soelaso dan Albiladiyah, 1975).

Tabel 2. Inovasi Seni Pertunjukan Drama Gong Pasca Dekade 2000-an

\begin{tabular}{|c|c|c|}
\hline No & Aspek & Deskripsi \\
\hline 1 & $\begin{array}{l}\text { Pengemasan } \\
\text { Cerita } \\
\text { (lelampahan) } \\
\text { drama gong }\end{array}$ & $\begin{array}{l}\text { Cerita panji/rakyat Bali yang } \\
\text { dikemas sesuai zaman sekarang } \\
\text { yang dilengkapi dengan sinopsis }\end{array}$ \\
\hline 2 & $\begin{array}{l}\text { Regenerasi } \\
\text { Pemain drama } \\
\text { gong }\end{array}$ & $\begin{array}{l}\text { Menyertakan pemain generasi } \\
\text { milenial }\end{array}$ \\
\hline 3 & Dialog & $\begin{array}{l}\text { Dialog drama gong menggunakan } \\
3 \text { bahasa (Bali, Indonesia, Inggris) }\end{array}$ \\
\hline 4 & $\begin{array}{l}\text { Setting/tata } \\
\text { panggung }\end{array}$ & $\begin{array}{l}\text { Pementasan drama gong bisa } \\
\text { digelar di dalam gedung dan } \\
\text { di luar gedung (alam terbuka), } \\
\text { didukung dengan aplikasi } \\
\text { teknologi panggung seperti } \\
\text { reflector cahaya/LCD dan } \\
\text { sebagainya }\end{array}$ \\
\hline
\end{tabular}

\begin{tabular}{lll}
\hline 5 & $\begin{array}{l}\text { Kolaborasi } \\
\text { dengan seni lain }\end{array}$ & $\begin{array}{l}\text { Pementasan drama gong bisa } \\
\text { diwarnai dengan nyanyian lagu } \\
\text { pop Bali, lawak, pop dangdut, } \\
\text { bebondresan, dan kesenian } \\
\text { lainnya. }\end{array}$ \\
\hline $6 \quad$ Media & $\begin{array}{l}\text { Pengemasan produk seni drama } \\
\text { gong dengan durasi waktu yang } \\
\text { diatur sedemikian secara serial } \\
\text { pertunjukan } \\
\text { drama gong }\end{array}$ & $\begin{array}{l}\text { sesuai alokasi waktu siarannya. } \\
\end{array}$ \\
& $\begin{array}{l}\text { Produk seni drama gong dikemas } \\
\text { dalam bentuk CD atau file MP4 } \\
\text { dan ditayangkan melalui channel } \\
\text { TV dan Youtube) }\end{array}$ \\
\hline
\end{tabular}

Sumber: Sugita, 2021

Kedua, adanya regenerasi pemain drama gong dengan menyertakan pemain generasi milenial. Dalam penggarapan kisah Jayaprana produksi Bali TV, generasi muda Bali memang sengaja diperankan lebih aktif, baik sebagai pemain, tata rias, seksi koreografi maupun kru pendukung lainnya. Terlibatnya pendukung drama gong dari usia muda ini juga untuk memastikan adanya proses pewarisan seni-budaya drama gong kepada generasi penerus.

Ketiga, inovasi dari segi dialog kekinian dengan menggunakan bahasa Indonesia dan Inggris sebagai selingan, disamping bahasa Bali sebagai Bahasa pertunjukan utamanya. Dalam versi kisah "Manik Gesing Buluh" garapan Sanggar Sancaya Dwipa, Bangli yang ditayangkan TVRI Bali dan channel Youtube (2020) misalnya, telah diperkaya dengan percakapan berbahasa Inggris oleh punakawan terkait aktivitas pemandu wisata (guide) yang sedang melayani turis asing di Bali. Begitu pun kisah "Jayaprana" garapan Sanggar Kayon Gianyar yang ditayangkan Bali TV (2021) juga menunjukkan percakapan dua orang punokawan terkait pandemi Covid-19 dengan menggunakan bahasa inggris. Ketika punakawan mengiringi patih Sawonggaling, di dekat kamar mandi, ia menyuruh temannya "wash your hand" (cucilah tanganmu), selalu pakai masker dan social distancing agar terhindar dari Covid-19.

Keempat, pementasan drama gong bisa digelar di dalam gedung dan di luar gedung (alam terbuka), didukung dengan aplikasi teknologi panggung seperti reflector cahaya, LCD dan sebagainya. Setting/tata panggung kisah Jayaprana produksi Bali TV (2021) misalnya, sengaja disetup di dalam gedung dan diluar gedung (alam terbuka) dengan mengambil latar di sebuah istana (puri) di Bali, layaknya sebuah sinetron sehingga suasananya lebih hidup dan lebih menantang. Penyajian ceritanya dengan adegan per episode, dengan manajemen yang lebih matang, melibatkan banyak ahli dibidang IT. Syuting drama gong di alam terbuka ini tentu didukung oleh tim 


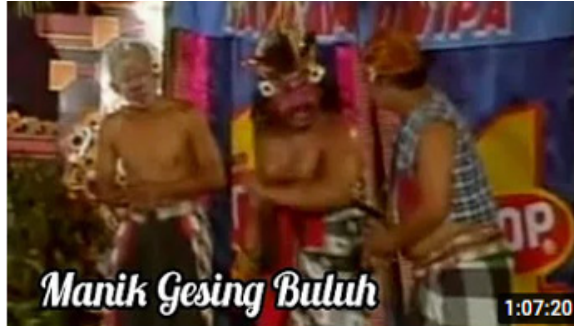

Manik Gesing Buluh (Episode 1) Sumber: youtube.com/manik+gesing+tvri (2021)

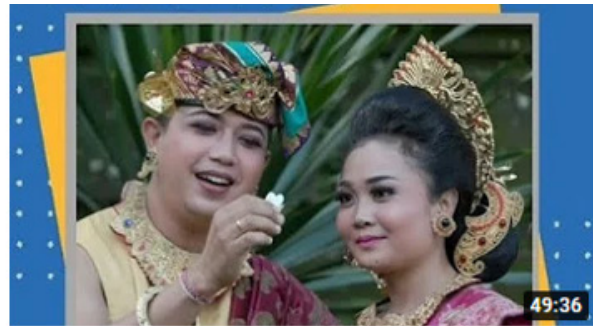

Jaya Prana (Episode 1)

Sumber:youtube.com/jayaprana+bali+tv (2021)

Gambar 1. Contoh Tautan Tayangan Drama Gong di Channel Youtube

kreatif Bali TV. Keberadaan tim kreatif yang berfungsi mengatur lakon yang perlu ditampilkan, manajemen yang professional, busana para pragina, dialog-dialog pragina, akting, pengaturan waktu dan lighting, jadwal pentas, tata rias, struktur dramatik pentas, pemilihan lokasi pentas, termasuk mengembangkan ide-ide kreatif yang bisa membaca selera penonton pada setiap jaman atau memberikan informasi tentang isu yang sedang popular.

Kelima, adanya kolaborasi antara seniman drama gong dengan seniman lainnya. Pementasan drama gong versi inovasi dalam dekade2000-an telah diperkaya dengan hadirnya berbagai kesenian modern, seperti lagu dangdut, unsur komedi, serta perlu berkolaborasi dengan kesenian lainnya yang mampu mendongkrak eksistensi drama gong, sebagaimana masa kejayaannya, pementasan drama gong pun digandengkan dengan kesenian lain yang kebetulan reputasinya tengah menanjak seperti pentas lagu pop Bali yang berkembang sejak 1990-an (Ardini, 2016), lawak, pop dangdut, bebondresan, tari jogged, dan kesenian lainnya. Seperti yang dapat disaksikan dalam Drama Gong Pengamen yang pentas pada tahun 2000, dipasang lagu dangdut berbahasa Indonesia. Untuk mengiringi penyanyi dangdut itu, tidak memakai musik gamelan tradisional, melainkan dari keyboard, yakni alat musik modern yang dimainkan seperti piano.

Keenam, inovasi dalam aspek pengemasan dan saluran pertunjukan drama gong. Sesuai dengan perkembangan teknologi, drama gong model baru telah dikemas dalam bentuk rekaman CD dan DVD yang kemudian cukup disimpan dalam bentuk file MP4 dalam flasddisk. Selanjunya, produk rekaman pementarasan drama gong dihidangkan kepada publik melalui salauran digital, baik melalui saluran siaran televisi maupun channel youtube.

Drama gong telah diunggah dalam jaringan youtube dengan durasi panjang ( \pm 60 menit), maupun durasi yang pendek (05 - 30 menit), dengan tujuan dapat menampilkan tayangan yang sesuai dengan harapan penonton. Pemanfaatan teknologi digital berupa youtube dan tayangan TV di era revolusi Industri 4.0 kini menjadi tuntutan agar seni pertunjukan drama gong bisa disebarkan secara lebih luas. Pementasan drama gong tidak hanya bisa ditonton oleh masyarakat Bali yang ada di Pulau Dewata, tetapi bisa ditonton oleh masyarakat di seluruh penjuru di muka bumi ini - sepajang ada jaringan internet.

Drama gong telah dikomodifikasikan: didesain sedemikian rupa, diproduksi dan didistribusikan ke konsumen sebagai tontonan sesuai tuntutan pasar (Adorno, 2002). Pengemasan tayangan drama gong melalui channel TV dan Youtube adalah bukti atas komodifikasi seni pertunjukan milik rakyat Bali ini. Komodifikasi menjadi suatu kebutuhan untuk menjamin keberadaan, pengembangan dan kesinambungan eksistensi Drama gong di Bali. Sebagaimana kesenian tradisional Bali lainnya, drama gong model baru amat potensial dijadikan sebagai atraksi wisata. Seperti dibuktikan oleh Ruastiti (2010), pementasan kreasi baru seni pertunjukan tradisional Bali mampu menarik perhatian para wisatawan. Seni pertunjukan drama gong inovatif bisa terus dikembangkan sebagai alternatif menu atraksi wisata yang menarik yang diterima oleh wisatawan yang berkunjung di Bali.

Respon Mayarakat Bali Terhadap Inovasi Drama Gong Inovasi drama gong model kemasan baru pasca dekade 2000-an merupakan bagian dari upaya merawat seni budaya masyarakat Hindu Bali agar tidak tergerus oleh arus perkembangan global. Inovasi seni pertunjukan drama gong ini mengindiasikan bahwa seni tradisional benasa Bali ini tetap eksis dan mampu mengikuti perkembangan zaman. Di era globalisasi saat ini, budaya lokal bisa bangkit, dikembangkan untuk mewarnai budaya nasional, bahkan budaya global (Collier, 1994). Tradisi dan senibudaya lokal termasuk drama gong bisa berpeluang besar sebagai pembentuk identitas budaya baru.

Kemasan baru seni pertunjukan drama gong terbukti mendapat sambutan hangat dari masyarakat Bali. Pertunjukan drama gong memperoleh respon yang positif oleh penggemarnya. Penggemar drama gong bukan hanya generasi tua masyarakat Bali yang memang menjadi penonton fanatik drama gong, generasi muda Bali pun juga menyukai seni tradisional Bali yang menggunakan Bahasa Bali ini. Sebagaimana ditunjukkan pada Gambar 2, beberapa episode drama gong yang ditayangkan oleh Bali TV dan TVRI Bali dalam dua tahun terakhir $(2020$ - 2021) masih ditonton oleh penggemarnya. 


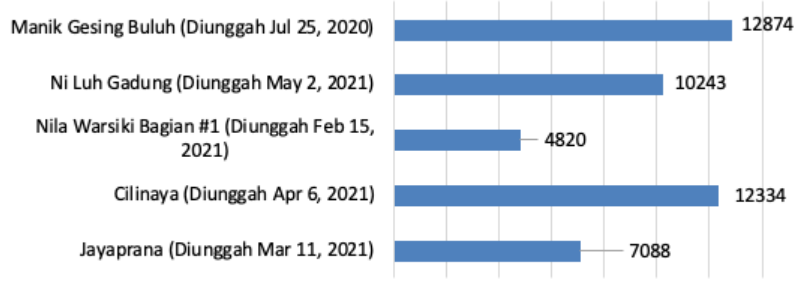

$0 \quad 2000400060008000100001200014000$

Gambar 2. Kunjungan Penonton Tayangan Drama Gong di Channel Youtube

(Sejak diunggah sd. 20 Juni 2021)

Sebagian masyarakat Bali masih menjadi penggemar setia seni pertunjukan drama gong. Hal ini dibuktikan dengan kunjungan penggemar tayangan drama gong di channel youtube (Gambar 2). Kisah Jayaprana yang diunggah sejak tanggal 11 Maret 2021 - 20 Juni 2021, telah dikunjungi (ditonton) oleh 7.088 orang, juga kisah Manik Gesing Buluh yang mulai diunggah sejak 25 Juli 2020 - 20 Juni 2021 telah ditonton sebanyak 12.874 orang. Ini menunjukkan bahwa_drama gong masih memiliki magnit tersendiri, digemari oleh rakyat Bali, karena drama gong menggunakan pendekatan, bahasa dan materi cerita yang komunikatif, sesuai dengan "bahasa budaya" sasarannya. Selaras dengan teori interaksionisme simbolik Blummer (Nurhadi, 2015), pemikiran dan bahasa drama gong bisa dimengerti oleh penontonnya. Penonton drama gong menilai bahwa materi edukasi drama gong cukup komunikatif sehingga mampu menggugah kesadaran dan partisipasi penontonnya.

Drama gong masih dicintai oleh pengemarnya, baik dari kalangan usia dewasa maupun usia muda yang menikmati tayangan drama gong melalui media TV dan Youtube. Penggemar drama gong dari usia muda adalah pewaris seni budaya Bali yang berupaya mempertahankan Bahasa Bali ini. Drama gong memang memiliki fungsi edukasi bahasa Bali, terutama yang menyangkut praktik sor siggih Bahasa Bali, serta pola umum bahasa Bali seperti penuturan salah seorang informan penggemar drama gong berikut ini.

"Karena pertunjukan langsung drama gong akhir-akhir ini semakin langka, maka penggemar drama gung, terutama dari kalangan anak muda Bali menonton drama gong via Yuotube. Disamping memperoleh hiburan, drama gong turut memberikan edukasi tentang bahasa Bali dan budaya Bali seperti menyampaikan tentang pentingnya filosofi Tri Hita Karana,yakni tiga prinsip keharmonisan penentu kebahagiaan umat Hindu Bali, yang meliputi: keharmonisan hubungan manusia Bali dengan Tuhan (parahyangan), dengan sesama manusia (pawongan) dan dengan alam (palemahan)" (Agung Patria, 31 tahun).

Penonton drama gong memperoleh pembelajaran tentang bahasa Bali dan nilai-nilai budaya Bali. Sesuai teori interaksionisme simbolik bahwa sebuah tanda atau simbol memiliki makna dan karakteristik khusus pada tindakan sosial dan interaksi sosial (Ritzer dan Douglas, 2007:292). Pesan berbahasa Bali dan seluruh adegan para pemain drama gong menjadi media yang efektif dalam proses pembelajaran budaya Bali kepada penontonnya. Hal ini dimungkinkan karena bahasa Bali digunakan sebagai bahasa utama dalam seni pertunjukan drama gong. Drama gong dinilai sebagai seni tradisi yang mampu merawat bahasa dan keberlanjutan kebudayaan Bali (Atmaja, 2009; Setia, 2006).

Secara umum, drama Gong memiliki dua fungsi, yaitu fungsi primer dan fungsi sekunder. Fungsi primer drama gong adalah sebagai sarana hiburan untuk masyarakat baik dalam upacara-upacara agama atau acara-acara khusus. Selanjutnya fungsi sekunder drama gong adalah sebagai media komunikasi masa, sebagai pengikat solidaritas masyarakat, sebagai media program pemerintah, dan sebagai fungsi pertunjukan (Widagama, 2017). Seni pertunjukan tradisional drama gong cukup efektif untuk menyampaikan kritik sosial dan pesan-pesan atau sosialisasi pembangunan melalui tokoh, pemain atau punokawan drama gong (Sugita, 2020, Setyawan, 2011).

Diantara kritik sosial yang disampaikan melalui lima kisah drama gong (Tabel 1) adalah menyangkut ketimpangan pembangunan di berbagai bidang, termasuk bidang kesehatan, pendidikan, sosial-ekonomi dan pariwisata Bali (Sugita,2020). Ketimpangan pembangunan bisa menimbulkan kegelisahan sosial. Dalam hal ini, humor diperlukan sebagai penampung aspirasi yang tidak resmi disuarakan oleh pelawak atau pemain drama gong. Humor sengaja dimunculkan sebagai sindiran, kritik atas ketidakseimbangan yang terjadi. Sindiran, ejekan, lelucon, dan protes merupakan ungkapan dari ketertindasan, dari kondisi powerlessness (Sobary, 1996).

Selanjutya, pesan sosialisasi pembangunan, antar lain disampaikan melalui serial drama gong dengan lakon Jayaprana" di Channel Bali TV (2020/2021) yang mensosialisasikan visi Pemerintah Provinsi Bali "Nangun Sat Kerthi Loka Bali": menuju Bali Era Baru, yaitu suatu Era yang ditandai dengan tatanan kehidupan baru, Bali yang Kawista, Bali yang tata tentram kerta raharja, gemah ripah lohjinawi, yakni tatanan kehidupan holistik. Pemerintah dan rakyat Bali berupaya menjaga tradisi dan budaya Bali sebagai modal utama pembangunan pariwisata budaya Bali (Sugita, 2020).

\section{SIMPULAN}

Drama gong merupakan bagian dari seni tradisional yang dicintai oleh masyaraat Bali. Eksistensi drama gong sampai dekade 2000-an telah mengalami berbagai inovasi. Inovasi drama gong mencakup: (1) kemasan cerita; (2) regenerasi pemain dengan melibatkan genearsi milenial; (3) dialog, (4) setting/tata panggung; (5) adanya kolaborasi 
dengan seniman non drama gong; dan (6) pemanfaatan teknologi digital dalam proses pengemasan dan penyaluran pertunjukan drama gong. Inovasi drama gong dalam dekade 2000-an ini mengindiasikan bahwa seni tradisional benasa Bali ini tetap eksis dan mampu mengikuti perkembangan zaman. Inovasi drama gong model baru memperoleh sambutan positif dari sebagian masyarakat Bali penggemar drama gong, termasuk penggemarnya dari kalangan anak muda Bali yang menikmatinya melalui TV dan Youtube. Sesuai perkembangan teknologi digital dewasa ini, pengemasan dan penayangan drama gong model baru melalui saluran media digital (TV, Youtube) patut dikembangkan.

\section{DAFTAR RUJUKAN}

Adorno, T.W. \& Horkheimer, M. (2002). Dialectic of Enlightenment. California: Stanford University Press.

Ardini, N. W. (2021). Produksi, Distribusi, dan Konsumsi dalam Industrialisasi Musik Pop Bali. Mudra Jurnal Seni Budaya, 31(1). https://doi.org/10.31091/mudra.v31i1.248

Atmaja, Jiwa. (2009). Tri Dasa Warsa Teater Mini Badung. Denpasar: Udayana University Press.

Collier, Mary Jane. (1994). , "Cultural Identity and Intercultural Communication”, dalam Samovar, Larry A. dan Porter, Ricard E. (eds), Intercultural Communication: A Reader, Berlmont: Wadsworth.

Dibia, I Wayan. (2007). Lampahan (Kumpulan Lakonlakon Seni Pertunjukan Bali). Denpasar: Institut Seni Indonesia (ISI) Denpasar.

Dibia, I Wayan. (2012). Geliat Seni Pertunjukan Bali. Denpasar: Arti Foundation.

Nurhadi, Zikri Fachrul. (2015). Teori-Teori Komunikasi. Bogor: Ghalia Indonesia.

Pateda, Mansoer. (2001). Semantik Leksikal. Jakarta: Rineka Cipta.

Putra, I Nyoman Darma. (2008). Modern Performing Arts As A Reflection Of Changing Balinese Identity, in "Indonesia and the Malay World"; http://www.tandfonline. com/loi/cimw20, Published online: 10 Apr 2008.

Putra, I Nyoman Darma. (2009). "Meninjau Kembali Sejarah Drama Gong"; https://balebengong.id/meninjaukembali-sejarah-drama-gong/; Diaksess 28 Juni 2009.

Riyadi, Soeprapto. (2001). Interaksionisme Simbolik (perspektif sosiologi modern. Malang: Averroes Press.
Ruastiti, Ni Made. (2010). Seni Pertunjukan Pariwisata Bali Kemasan Baru Dalam Pespektif Kajian Budaya. Yogyakarta: Kanisius.

Ruastiti, Ni Made. (2020). "Strategi Membangun Seni Budaya Di Era Digital (Orasi Ilmiah). Jayapura: ISBI Tanah Papua.

Ritzer, George-Douglas J. Goodman. (2007). Teori Sosiologi Modern. Jakarta : Kencana Predana

Schlechtendahl, J., Keinert, M., Kretschmer, F., Lechler, A., \& Verl, A. (2015). Making existing production systems Industry 4.0-ready. Production Engineering, Vol. 9, Issue. 1 , pp.143-148

Setia, Putu. (2006). Mendebat Bali. Denpasar: PT Pustaka Manikgeni.

Sedyawati, Edi. (2007). Keindonesian dalam Budaya. Jakarta: Wedatama

Sobary, Muhammad. (1996). Kebudayaan Rakyat Dimensi Politik dan Agama. Yogayakarta: Bentang.

Sobur, Alex. (2004). Analisis Teks Media. Bandung: PT Remaja Rosdakarya.

Soedarsono. (2000). Masa Gemilang dan Memudar: Drama gong Gaya Yogyakarta. Yogyakarta : Tarawang

Soelarso, B. dan S. Ilmi Albiladiyah. (1975). Pertunjukan Rakyat Drama Gong dari Bali. Proyek Pengembangan Media Kebudayaan Ditjen Kebudayaan Departemen Pendidikan dan Kebudayaan RI Jakarta.

Sugita IW, Setini M, Anshori Y. (2021). Counter Hegemony of Cultural Art Innovation against Art in Digital Media. Journal of Open Innovation: Technology, Market, and Complexity. 2021; 7(2):147. https://doi.org/10.3390/ joitmc 7020147

Sugita, I Wayan. (2016). Dinamika Pementasan Drama Gong di Bali. Denpasar: Sekdut Bali Performing Arts Community.

Sugita, I Wayan. (2020). Drama Gong sebagai Media Pendidikan dan Kritik Sosial, Jurnal Kajian Bali, Vol 10 No 2 (2020), https://ojs.unud.ac.id/index.php/kajianbali.

Sugiartha, I Gede Arya, (2006). Pengaruh Gamelan Gong Gebyar Terhadap Gamelan lainnya; Mudra Volume 18, No. 1 Januari 2006. 
Suarta, I. M. (2018). Nilai-nilai Filosofis Didaktis, Humanistis, dan Spiritual dalam Kesenian Tradisional Macapat Masyarakat Bali. Mudra Jurnal Seni Budaya, 33(2), 191-199. https://doi.org/10.31091/ mudra.v33i2.364

Widya Sastra.Setyawan, Arya Dani. (2011). "Fungsi Seni Pertunjukan Tradisional", (Online), Tersedia dalam http://aryadanisetyawan.blogspot. com/2011/11/fungsi-seni-pertunjukan-tradisional-di. html). Diakses 25 Agustus 2015.

Widagama, Ngakan Putu Gatam. (2017). Pementasan Drama Gong Wijayakusuma Sebagai Media Komunikasi Tradisional Di Kelurahan Abianbase Kecamatan Gianyar Kabupaten Gianyar. Jurnal penelitian Agama Hindu, Vol 1, Nomor 2, Oktobewr 2017. 